district, it happened that, after one or two mild seizures, complete recovery ensued. Much more frequently there was no intermission of perfect health; the pulse, skin, and tongue might be in their normal state, or nearly so, but the capability of the individual to resist the attack was much lowered ; generally, too, during this partial recovery, there continued the sense of prostration, the loss of appetite and of energy, and a dull pain in the neighbourhood of the liver and spleen : remaining, as the majority had to remain, subject to malarious influences, yet properly treated and sufficiently fed, the attacks became more distant, quotidian becoming tertian, quartan, erratic, or ceasing altogether. It is perhaps hardly necessary to say that the stages were not always well marked. We had malaria without fever. Sometimes, but rarely, typhoid symptoms occurred ; there was no longer an intermission, scarcely a remission ; it became a continued fever with accessions at regular or irregular periods ; in these we had the typhoid symptoms only before death. On examination post mortcm, it was found that Peyer's patches were never involved. The relative frequency of quotidian, tertian, quartan, and erratic was, according to the Civil Hospital returns, as follows :- Quotidian, 82.90; tertian, I3,08; quartan, 0.45 ; and erratic, 3.57 ; and my experience would yield somewhat similar results. The sequelæ were hæmorrhages, anasarca, ascites, hæmaturia, constipation, diarrhœa, and, by far the most fatal, dysentery.

The post mortem appearances were very various; these depended, to some extent, upon whether the patient had yielded to one sudden, sharp attack, or whether he died only after having made a stout resistance. I am greatly indebted to my friend Dr. Dickson of Grande Rivière for information on this subject, and I regret that I am not able to furnish the more exact data that his necropsical journal would afford. There were generally present cerebral congestion and effusion ; after many attacks, softening of the brain, which, too, was often stained of a yellow colour. The heart was flaccid; the ventricles contained yellow fibrinous clots, which sometimes extended to a considerable distance into the aorta and pulmonary artery ; the liver was enlarged, congested, softened, and friable-more rarely hard and shrivelled; the spleen much enlarged, and after numerous seizures, of a dark slaty colour, and softened; the mucous membrane of the stomach and intestinal canal was very much congested; the kidneys normal, or flabby, white, and bloodless ; more rarely shrivelled and dry; more frequently softened.

The treatment was that usually adopted:--emetics, purgatives, and antiperiodics during the intermission; stimulants, diaphoretics, and counterirritants during the paroxysm. It was, I think, pretty generally established that a large dose of quinine, administered about an hour before the expected attack, modified, shortened, or postponed it. I may here mention some large doses of that alkaloid. Usually from three to five grains were prescribed ; after a time, 10, 20, 30, 40 grains, the last being the largest dose I ever employed, or took. I have known a hundred grains given in two doses, with an interval of twelve hours between them; and Dr. André speaks of its being not uncommon to administer I6o grains in the twenty-four hours. Arsenic, iron, beeberine, strychnine, sulphur, hyposulphite of soda, Warburg's tincture, and other remedies were tried, (especially at a time when quinine sold for $£ 19$ an ounce,) and found of little or no use. Carbolic acid administered by mouth was valueless, but, hypodermically injected, gave favourable results. It was to this mode of treatment I alluded in the early portion of my paper. I used a solution containing two minims of the crystallised acid to a drachm of water, and, when I could do so, injected from twenty to forty minims a short time before the attack was expected, and at the same hour on two or three consecutive days. I regret that I was only able to treat in this manner thirty-six cases in hospital and dispensary. Of these twenty-two were cured, but eight relapsed after an interval of from six to thirty days ; in seven cases failure was more or less complete, and the remaining seven not having reported themselves at the Dispensary, the result in these cases was not positively known.

The time during which the fever-poison will remain, and the very peculiar manner in which it will exhibit its power, its erratic course, and its periodicity, may be shown in my own case. My last attack in Mauritius-a very mild one-occurred in March 1869 . I arrived in London in May, and spent more than six months there and at Reesmouth on North Tyne, quite free from fever. Attending the November meeting of the Northumberland and Durham Medical Society, I experienced my first attack in England in the library of the Infirmary, and, by the time I reached my hotel, it became a pretty sharp one. I had a return every twenty-seven days for five months, remaining perfectly well during each interval. Although it is now more than four months since the last seizure, I need not say that I do not consider myself safe.

The inferences and opinions deduced from the facts herein narrated, with certain advice, were duly forwarded by me to the colonial office for consideration, and, belonging as they do to that department of government, are not for publication.

\section{ANOTHER SOURCE OF LEAD-POISONING.}

By ALFRED WILTSHIRE, M.D., M.R.C.P.Lond.,

Junior Physician to the West London Hospital ; Physician to the Samaritan Hospital for Women and Children: Physician to the British Lying-in Hospital; late Medical Inspector to Her Majesty's Privy Counril.

I AM desirous of recording a case of lead-poisoning, in which the discovery of the source whence the metal was derived was somewhat diffi. cult, although, as will be seen, it was superficial enough.

A middle-aged man, a coach-builder by trade, came to me complaining of pains which had troubled him for years, and for which he could get no relief. The man was gouty, and the pains he suffered from partook of the gouty character; occasionally during an exacerbation developing into ordinary arthritic gout. His aspect was very much that of chronic Bright's disease ; he was anæmic and pasty-looking : but repeated careful examinations of his urine excluded the possibility of that disease being present.

Knowing the influence of lead in predisposing to gout, I looked to the gums, and there found a marked blue line. I now set myself to discover the source of the metal, and made careful inquiries in every direction that suggested itself to me. To begin with, the man assured me that he had nothing to do with painting or with the metal-work of coach-building; he confined himself exclusively to the wood-work. I then investigated the character of the water-supply, and looked into the possibility of his food or drink being the agents whereby the poison was introduced into his body, but with negative results. I was baffled at every turn; yet I felt convinced that his system was impregnated with lead, and the happy results of treatment by iodide of potassium confirmed me in this belief.

Determined not to be frustrated if I could possibly avoid it, I one day asked him to describe to me in detail exactly what his work was, thinking it just possible that he might use leaden rivets or something of that kind in fastening his work together. He then told me, with an expression of surprise, that he had not thought of it before, that he was a coach panel-maker, and that the panels were fitted into carriages by means of white lead, no screws or bolts of any kind being used. Here, then, was the source of the metal which, superficial as it may appear, for some time eluded discovery. I have since learned that carpenters, joiners, cabinet-makers, and other workers in wood, not unfrequently use white lead for fastening joints, etc.

I need hardly say that the foundation of the man's sufferings being disclosed, he soon got relief. He told me he had been a sufferer for years, and had frequently been under the treatment of surgeons in general practice, and had consulted one or two well-known physicians, but, beyond relief of the more urgent symptoms of acute gout, he could get no ease. Iodide of potassium and iron, Epsom salts and sulphuric acid, cured him.

57, Wimpole Street, November 187 o.

\section{ABNORMAL FORMATION OF THE VAGINA.}

SOME months since, I was called to attend a woman in her first confinement. On examination I could not pass my finger more than an inch in any direction into the vagina. It was some time before I could feel on the soft flat muscular substance which met my fingers anything like an os uteri. I at last detected, lying very much forward and against the pubes, a slit feeling something like an os. I could not make out the presentation ; and, as the pains were irregular and no urgency about the case, I gave a dose of opium and went to bed. On visiting the case ten hours afterwards, I found that one foot had descended through the opening by the pubis, and the other made a rent for itself through the centre of what I may describe as the false or abnormal floor of this vagina, which seemed of average capacity. I put back this foot and brought it down with the other. I could now, on passing my finger through the rent in the centre, feel the os and uterus, which was well dilated and very moveable. I thought for some time that the opening through which the feet protruded seemed inclined to dilate sufficiently to admit of the child passing, but it was not so ; therefore, with the traction which it was necessary to make, and the size of the child, the two rents soon became one. Even after this, there was much difficulty in delivering, the uterus seeming to come down with the child as traction was made. I gave ergot, used external pressure, and made as gentle traction as possible, although much force was required before delivery was completed. There was a good deal of hæmorrhage, evidently from the torn muscle, which made me glad I did not divide it with the knife, its vascularity seemed so great. The woman made a very good recovery. This a bnormal muscle again contracted, and keeps up the uterus as before.

C. ]. Denny, Malvern Wells. 


\section{HYDROA AND ITS ALLIED DISEASES.}

THE following table shews the principal points in the cases of Hydroa which have already been published in the JouRnaL (see July 23 rd, p. 86), and in four which have been since noted. The first four cases in the list are those of M. Bazin.

Table shozuing the Principal Points in Cases of Hydroa.

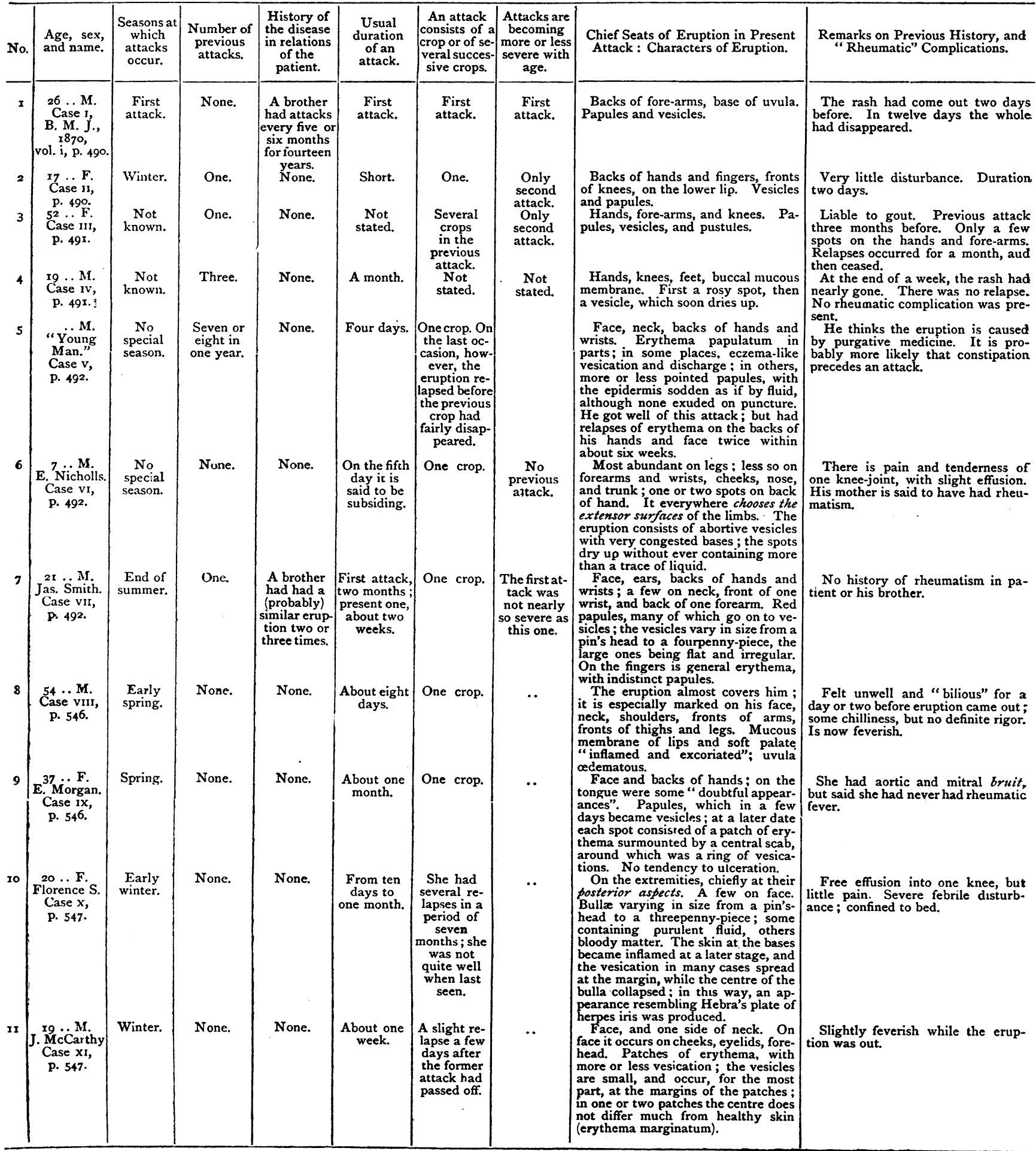


Table showing the Principal Points in Cases of Hydroa (continued).

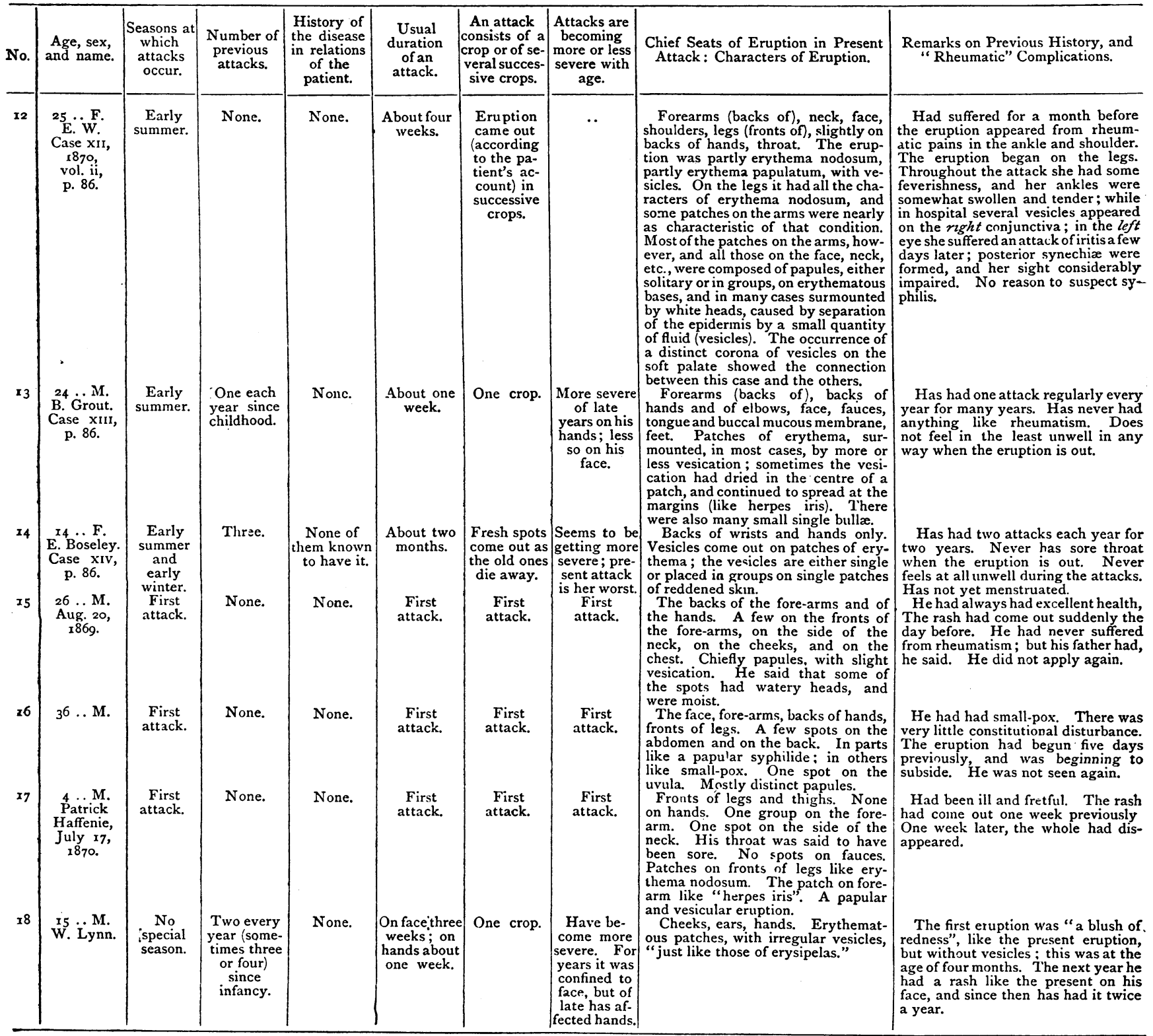

CASE Xv. A Papulo-Vesicular Eruption on the Backs of the Hands, Fore-arms, and Face (Hydroa).- A man, aged 26, applied at the Hospital for Diseases of the Skin, Blackfriars, August 20, 1869, with a vesiculo-papular eruption. On the backs of the fore-arms and on the backs of the hands was a symmetrical eruption of papules with an abortive attempt at vesication. He said that some of the spots had "watery heads" and were moist. Most of them when seen were without fluid contents. There were a few spots also on the fronts of the fore-arms, on the side of the neck, on the cheeks, and on the chest. The rash had come out suddenly the day before he came under care, and this was his first attack. He had never previously had any skin-disease at all, as far as he knew. He was robust and in good health. When asked as to rheumatic affections, he said he had never suffered in any way, but his father had had rheumatism. He did not apply again.

CASE XVI. An Eruption resembling Small-pox occurring on the Face, Fore-arms, -Backs of Hands, and Fronts of the Legs: first attack.-An Irishman, aged 36 , was attending as an out-patient, under the care of Dr. Sutton, at the London Hospital, for pain in the back of three months' duration, when an eruption appeared, for which he was trans- ferred to the care of Mr. Tay. It occurred copiously on the face, forearms, the backs of the hands, and the fronts of the legs, and there were a few spots on the abdomen and on the back. On the face the eruption was merely papular, and looked not unlike a syphilide. On the fore-arms, hands, and legs were a number of distinct papules, each having an inflamed base, and on the summit either a vesicle or a pustule. In some, the crust on the apices had fallen in in the middle, giving an appearance of depression not at all unlike that of small-pox. Dr. Sutton called attention to this, but remarked that the position of the eruption on exposed parts was the reverse of what occurred in smallpox, and the man had no premonitory symptoms, and was not ill enough. On examining the throat, there appeared to be one pustule on the uvula, but it was not very definite. The man stated, August r, that he had noticed the first spots on the fore-arms four days previously. He did not admit so much disturbance of digestion as patients suffering from this malady generally do. This was his first attack. He had never had any "rash on his skin" before. He had had small-pox. The case seemed clearly one of hydroa. The position and character of the eruption agreed with the cases previously described. Though only 
the sixth day of the outbreak, the fluid in the vesicles was-evidently drying up, and the whole eruption just beginning to subside.

CASE XVII. Hydroa in association with Erythema Nodosum in a Child: Eruption chiefly on Lozver Extremities. - Patrick Haffenie, aged 4, was brought as an out-patient to the Hospital for Diseases of the Skin, Blackfriars, July I 7,1870 . On the front of each shin was a patch of redness of skin, with slight œedema and very painful to the touch, exactly resembling patches of erythema nodosum. Scattered over the legs and thighs were numerous papules, and papules with more or less vesication on the surface. Each spot was quite distinct from its neighbour, and there was no tendency for any to coalesce. The spots were much fewer on the backs of the legs and thighs than in front. There were no papules, etc., on the hands, but there was one group on the back of the right fore-arm, below the elbow, resembling the so-called " herpes iris." There was one vesicle on the side of the back. There was no eruption to be seen on the fauces, but his mother said that his throat had been sore. The eruption began the week previously. $\mathrm{He}$ had been noticed to be rather ill and fretful before it came out, and he seemed decidedly ill and feverish when seen, and he had lost his appetite. One week later (July 26) the rash had quite disappeared, his appetite had returned, but he still looked pale. He had simply been ordered a little alkaline medicine.

\section{FOREIGN BOIY IN`NASAL CAVITY: REMOVAL AND SUBSEQUENT RHINOPLASTY.*}

\section{BY J. H. BAR TLE T, M.D.,}

Surgeon to the East Suffolk Hospital.

Henry Goodmax, aged 29, sailor, living at Chelmondeston, was ad mitted into the East Suffolk Hospital on January 5 th, I864. He was shooting on the river Orwell, when his gun burst and smashed in a portion of the frontal bone; and a large piece of the gun.barrel lodged in the frontal sinus between the orbits. He was then attended by Mr. Bullen, who extracted two pieces of metal weighing five ounces. For some days his life was despaired of; but at the end of five weeks his health so much improved that he was able to leave his bed. During the seventeen weeks that he was in the hospital, seven pieces of bone came out of his head.

He left the hospital on May 3 rd, 1864; but he was unable to com mence work until December. From that date he continued to work with a handkerchief over the opening between the orbits until Decem ber 8th, 1869, when he was readmitted to the hospital for the purpose of having the remaining portion of dead bone removed. On admission, the supposed dead bone could be felt, quite movable, both through the opening between the orbits and through the nostril. There was a small quantity of purulent discharge from the nostril, which kept up constant irritation. The sight of the left eye was quite destroyed by the accident. Through the frontal opening, which was about one inch in diameter, the substance was easily grasped by a pair of forceps; but all attempts at removal failed. It was decided, upon consultation with my colleagues, to attempt to crush the substance, which, to the astonishment of all, we found, upon drilling, to be a piece of iron.

On January Ioth, I870, chloroform was administered, and the open ing between the orbits was enlarged; but, it being found that the foreign body could not be extracted, a V-shaped portion of the nasal bone was sawn through, and the opening still further enlarged by bone-forceps. The substance was then grasped by a pair of very strong forceps, and was extracted. It proved to be the breech and screw of a large duckgun, and which weighed three ounces and six grains. The man went on well after the operation, and was discharged.

On April 1 3 th, 1870 , he was readmitted in order to have the opening in the nose closed by a rhinoplastic operation. His general health had much improved since he left the hospital.

On April 16th, the shape of the flap was marked out upon the forehead with tincture of iodine, in an oblique direction, to avoid twisting the neck of the flap. Chloroform was administered; a thick flap was dissected from the forehead, and secured to the pared edges of the opening by half a dozen sutures; the edges of the wound on the forehead were brought together by two hare-lip pins; and the whole was dressed with lint covered with cotton-wool slightly carbolised. The room was kept at an even temperature night and day. The patient was supplied with beef-tea, brandy, eggs, sherry, etc. On the sixth day, the pins were removed from the forehead; and the wound had healed by first intention. Some of the sutures were removed from the flap, which was warm, healthy, and uniting. From this time all went on well, with the excep- tion of one side, which soon healed, after having been touched with a hot probe. The patient was discharged from the hospital with the aperture completely closed. $\mathrm{He}$ is now in better health than he had been for the six years since the accident.

\section{CLINICAL MEMORANDA.}

\section{FRACTURE OF THE SKULL: TREPHINING: RAPID RECOVERY.}

WM. H. Clayton, aged 8 , a factory operative, in passing through a passage in a mill on July I Ith, I870, climbed up a ladder and put his arm around a shaft (as if to ride on it) which revolved rapidly at about eight feet from the ground and three from the ceiling. $\mathrm{He}$ was quickly spun round it, and must have described two revolutions at least, when he was dashed with great force against the flags beneath. When I saw him, about twenty minutes after the accident, he was completely insensible, bleeding from the nose, and the right side of his body was violently convulsed. The pupils were dilated. The surface of the body was cold and beginning to assume a livid appearance, but presented no wound. On examination of the head, I found a fracture (without any wound of the scalp) in the left side, running through the parietal bone and extending forwards as far as the root of the nasal bone; how far backwards 1 could not exactly trace, but the superior middle portion of the parietal bone, through which the fracture ran, gave a sensation as of a depressed spot; and, on pressing this with the fingers, the convulsions were very much increased. I shaved the affected side of the head, and raised a V-shaped flap of the scalp directly over the point of depression. The bone was not at all depressed, although convulsions still presented themselves on pressure. I proceeded to trephine; and when the bone was removed I replaced the flap, fixed it with a few interrupted points of silk suture, and applied cold water dressing. I left with orders to be informed if any change occurred before the time appointed for my return. Four hours afterwards, I found him sleeping, but uneasily. The convulsions had ceased a quarter of an hour after the operation. The pupils were less dilated. He spent a restless night, and was still tinconscious next morning. He passed a quiet day, sleeping most of the time. After this, he gradually improved, and on July I6th was allowed to get up at his own request. From this day he continued to improve so rapidly, that on the 2Ist he wished very much to walk a distance of five or six miles. To this I would not consent. In about three weeks, he resumed his work in the mill, and has continued at it, in good and unimpaired health, up to the present date, October I6th.

REMARKS. - This case is remarkable for the positive symptoms of compression pointing decidedly to a certain spot, where, on laying bare the bone, no depression of it was found, either in the external table or in the internal table after trephining, nor was there any extravasa. tion of blood beneath it to account for such symptoms. That the boy might have recovered without the operation, I am led to think, from the appearances presented by the parts operated on. But what surgeon would not be induced to operate under such circumstances on a patient almost moribund, with a view to relieve symptoms so significantly pronounced? Charles W. ThORP, Todmorden.

Formation of Urea in The Liver.-Dr. Cyon of St. Petersburg has published in the Centralblatt fïr Medizin. Wissenschaft an account of some researches made by him, from which he infers that urea is formed in the liver. Blood withdrawn from the carotid arteries of dogs was rapidly defibrinated; part of it was placed in an apparatus arranged for propelling it through the liver by mechanical pressure. Three cannulæ were introduced, one into the inferior vena cava, a second into the hepatic vein, and a third into the portal vein. The first of these was connected with an aspirator consisting of two cylinders partly filled with mercury; the other two were connected with the vessels containing blood. The blood was now allowed to flow through the liver; and, after it had flowed through the organ several times, the quantity of urea was determined by Liebig's method, and compared with that in the ordinary blood of the animal. The blood which had passed through the liver was found to contain the larger quantity of urea. In Ioo cubic centimetres of blood sent twice through the liver of a moderate sized dog, there was 0.14 gramme of urea; in the same quantity of blood not so treated, the amount was 0.09 gramme. When the blood was sent through the liver four times, the amount of urea in Ioo cubic centimetres was 0.176 gramme; that in a similar quantity of the ordinary blood of the animal being 0.08 gramme.-Wiener Medizin. Wochenschr., October 29th, 1870. 